ORIGINAL ARTICLE

\title{
Comparative Microbiological Evaluation after Caries Removal by Various Burs
}

\author{
Rani Somani ${ }^{1}$, Rohan Chaudhary ${ }^{2}$, Shipra Jaidka ${ }^{3}$, Deepti J Singh ${ }^{4}$
}

\begin{abstract}
Aim: The aim of the study was to compare the caries removal efficacy in terms of bacteriology and efficiency in terms of time taken by conventional and smart burs.

Materials and methods: A total of 40 extracted permanent molars with occlusal caries were selected for this study. These teeth were split at the center of carious lesion buccolingually, in order to obtain two similar halves. Thus, 80 samples were obtained in this way and were randomly divided into 2 groups of 40 samples each. Caries was removed using conventional burs in group I and polymer bur Smartprep (SS white) in group II. The time involved in caries removal was measured for both the groups. After excavation of all carious lesions, the samples were decalcified, dehydrated, and embedded in paraffin wax from which thin sections of $5 \mu \mathrm{m}$ were obtained, which were histologically evaluated for bacterial presence under a light microscope.

Results: An intergroup comparison between conventional bur (group I) and smart bur (group II) showed a statistically nonsignificant difference in terms of the presence of microorganisms after caries removal with a $p$ value of $0.073638(p>0.05)$. However, the time taken for caries removal was significantly more for smart burs than diamond burs with a $p$ value of $0.001(p<0.05)$.

Conclusion: The polymer burs were found to be as effective as the conventional burs in terms of microbial presence after caries removal, but are more time-consuming than conventional burs.
\end{abstract}

Keywords: Conventional bur, Dental caries, Knoop hardness, Polymer bur (Smartprep).

International Journal of Clinical Pediatric Dentistry (2019): 10.5005/jp-journals-10005-1678

\section{INTRODUCTION}

Dental caries is a multifactorial disease that starts with microbiological shifts within the complex biofilm and is affected by flow and composition of saliva, exposure to fluoride, consumption of dietary sugars, and by preventive behaviors. It is considered an infectious disease, involving various microbiological populations. ${ }^{1}$ It can be divided into a superficial or outer infected dentin layer that is typically demineralized and contaminated with bacteria and cannot be re-mineralized, indicating that it should be removed completely and an inner affected dentin layer (which is less contaminated) with an intact, cross-banded ultrastructure of collagen matrix that can be remineralized. ${ }^{2}$

The conventional method of caries removal include caries removal with spoon excavator, stainless steel round bur, diamond bur, or tungsten carbide bur in slow speed. The disadvantage of these methods is that they aggressively remove both the infected and the affected dentine. On the contrary, the main objective of conservative method is to selectively remove the infected dentin, leaving the affected dentin intact for re-mineralization. ${ }^{3}$ A novel, recently proposed, self-limiting concept in mechanical caries removal has been brought to existence by the introduction of a Polymer bur (SmartPrep, SS White Burs, Inc., Lakewood, NJ, USA). The paddle-shaped bur has a unique flute design, and is constructed from a medical-grade polyether-ketone-ketone (PEKK), with a particular knoop hardness of $50 \mathrm{KHN}$. Thus, these burs can easily remove the soft carious dentin, but when they come in contact with the hard dentin, they blunt out preventing unnecessary removal of the affected and the healthy dentin. ${ }^{4}$

Thus, the aim of the study was to compare the caries removal efficacy in terms of bacteriology and efficiency in terms of time taken by conventional and smart burs. \begin{tabular}{l}
\hline${ }^{1-4}$ Department of Pedodontics and Preventive Dentistry, DJ College of \\
Dental Sciences and Research, Modinagar, Uttar Pradesh, India \\
Corresponding Author: Rani Somani, Department of Pedodontics \\
and Preventive Dentistry, DJ College of Dental Sciences and Research, \\
Modinagar, Uttar Pradesh, India, Phone: +91 9810950754, e-mail: \\
somanirani@gmail.com \\
How to cite this article: Somani R, Chaudhary R, Jaidka S, et al. \\
Comparative Microbiological Evaluation after Caries Removal by \\
Various Burs. Int J Clin Pediatr Dent 2019;12(6):524-527. \\
Source of support: Nil \\
Conflict of interest: None
\end{tabular}

\section{Materials and Methods}

The in vitro study was conducted at the Department of Pedodontics and Preventive Dentistry at Divya Jyoti College of Dental Sciences and Research, Modinagar, Uttar Pradesh. An estimated 40 extracted permanent molars with occlusal caries were collected and cleaned using ultrasonic scaler to remove the debris. They were used within 3 months of collection as per recommendations of Occupational Safety and Health Administration (OSHA). ${ }^{5}$ Prior to their inclusion in the study, each carious lesion was analyzed according to the Erickson's criteria, i.e., color (brown-to-black) and hardness of the lesion (medium consistency-resistance to probing but readily penetrated when tested with a sharp probe). Sampled teeth were stored in $0.1 \%$ thymol solution at room temperature to avoid dehydration for the entire duration of the study. The inclusion criteria consisted of (1) carious teeth involving enamel and dentin, (2) teeth with intact buccal/lingual surface, (3) teeth free from fluorosis, and (4) teeth without restoration. The exclusion criteria for the study included (1) teeth with any developmental anomaly, 
(2) teeth with proximal caries and pulpal involvement, (3) teeth with restoration and fractured crown, (4) presence of white spot lesions, and (5) hypoplastic or hypomineralized teeth.

All 40 teeth were sectioned through the center of the lesion buccolingually into two halves amounting to a total sample size of 80 sections, which were randomly divided into two groups: group I $(n=40)$-caries were excavated using conventional burs; group II $(n=40)$ — caries were excavated using smart burs (Flowchart 1).

\section{Method of Caries Removal}

In group I, the carious lesion was excavated using a brand new conventional bur with a slow-speed micromotor handpiece at $800 \mathrm{rpm}$ from the occlusal aspect until hard dentin was detected using a straight probe. The complete removal of caries was checked according to Erikson criteria, i.e., optical (color) and tactile hardness. The color was checked visually and hardness of the lesion was checked by the dental explorer until a leather-hard texture and sharp scratching sound was heard. In group II, caries was excavated using new Smartbur, no. 2, 4, and 6 SS White Co (polymer burs) according to the lesion's size. Caries was excavated with circular movements starting from the center of the lesion to the periphery, as recommended by the manufacturer. Excavation was stopped when the instrument became macroscopically abraded and blunted and was no longer able to cut through the affected area. The same procedure was repeated for all the sections of both the groups.

\section{Time Assessment}

The preparation time for each caries-removal technique in both the groups ( $n=80$ ) was evaluated using a stopwatch. The total time taken for caries removal was calculated from the beginning of removing caries till its complete removal in seconds in both the groups.

\section{Preparation of Samples for Bacteriological Evaluation}

After caries removal in both the groups, the samples were fixed in $10 \%$ neutral buffered formalin for 6 hours prior to decalcification. After thorough washing with tap water, the samples were suspended in containers with help of thread such that the tooth was completely immersed in the decalcifying solution $(10 \%$ $\mathrm{HNO}_{3}$ ). Decalcification of samples was checked by piercing them with fine needle or pinching through a dental probe or explorer. Decalcification was confirmed if the needle or probe goes through the samples, implying that the samples are completely soft. After confirming the completion of decalcification, the samples were washed thoroughly under running tap water for minimum of 30 minutes to remove the remaining decalcified fluid. The tissue dehydration was carried out by passing it through ascending degrees of ethanol (50\%, 60\%, 70\% and 90\%) and cleared in xylene for one hour using an automatic tissue processor (Yorco).

Flowchart 1: Division of sample

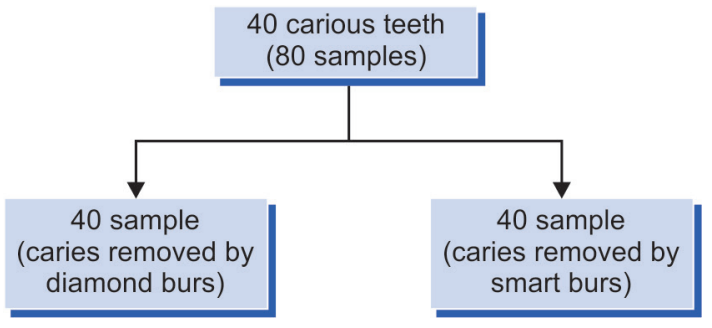

These samples were then embedded in paraffin wax and blocks were prepared. Serial sections of $5 \mu \mathrm{m}$ were cut from the block using rotary microtome. ${ }^{6}$ The samples were then mounted on glass slides coated with egg albumin and stained with eosin and hematoxylin. They were observed under the light microscope (40X) and were assessed for the presence/absence of microorganisms on remaining dentine. The presence of microorganisms was denoted with numeric value 1 and the absence was depicted with 0 by the observers. Images were captured and analyzed by using B540 software (Figs 1 and 2).

\section{Results}

The data for this study were analyzed using Chi-square statistical test for testing the efficacy of caries removal with conventional and smart burs and paired student's t test for analysing the time taken in caries removal. For the purpose of statistical interpretation, a $p$ value of $\leq 0.05$ was considered statistically significant.

An inter-group comparison between conventional bur (group I) and smart bur (group II) was found to be statistically nonsignificant in terms of presence/absence of microorganisms after caries removal by either of them. The $p$ value obtained was 0.073638

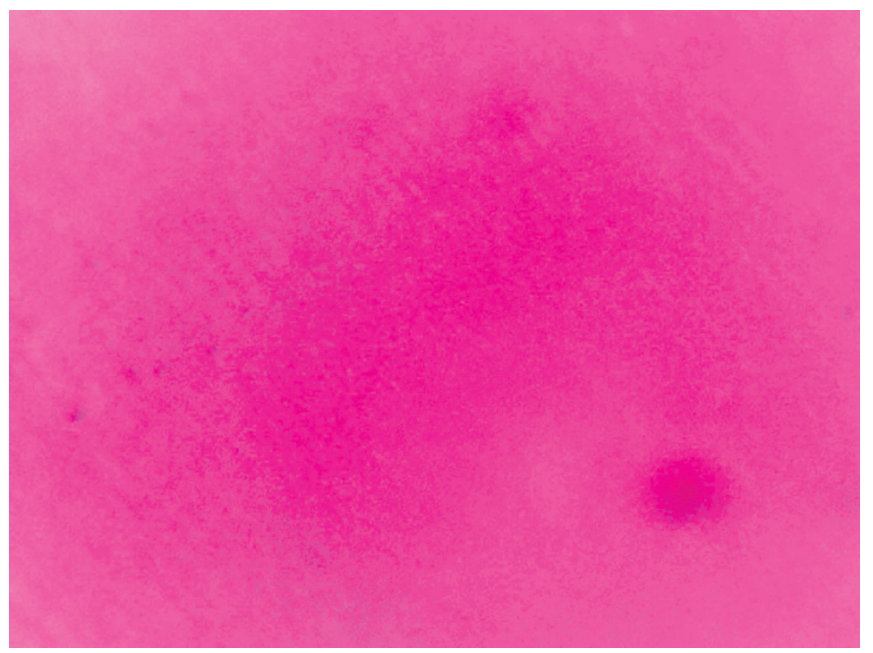

Fig. 1: Microscopic view of the slide after caries removal using conventional caries removal

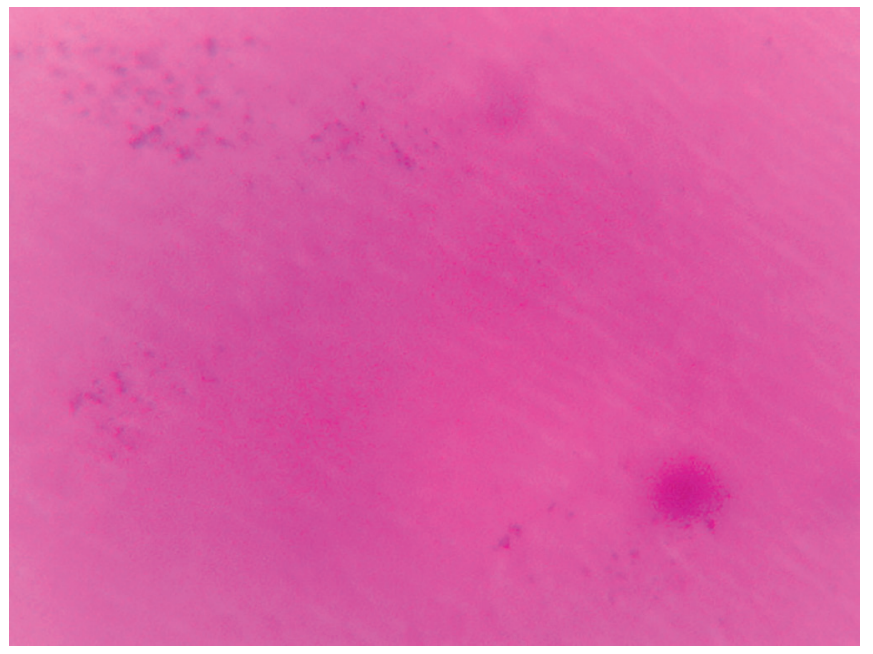

Fig. 2: Microscopic view of the slide after caries removal using smart bur 
Table 1: A comparison of microbial presence in the conventional bur group (group I) and smart bur group (group II)

\begin{tabular}{llllll}
\hline Groups & $N$ & Mean & Std. deviation & Chi-square value & $p$ value* \\
\hline $\begin{array}{l}\text { Conventional bur } \\
\text { (group I) }\end{array}$ & 40 & 0.4 & 0.49 & 3.2 & 0.073638 \\
Smart bur (group II) & 40 & 0.6 & 0.51 & & (non-significant) \\
\hline
\end{tabular}

$p<0.05$-significant; $p>0.05$-nonsignificant

Table 2: A comparison of time taken for caries removal by conventional bur (group I) and smart bur (group II)

\begin{tabular}{llllll}
\hline Groups & $N$ & Mean (seconds) & Std. deviation & t value & $p$ value* \\
\hline $\begin{array}{l}\text { Conventional bur } \\
\text { (group I) }\end{array}$ & 40 & 79.3 & 9.19 & 2.393 & 0.001 (significant) \\
Smart bur (group II) & 40 & 147.5 & 13.16 & & \\
\hline
\end{tabular}

$p<0.05$-significant; $p>0.05$-nonsignificant

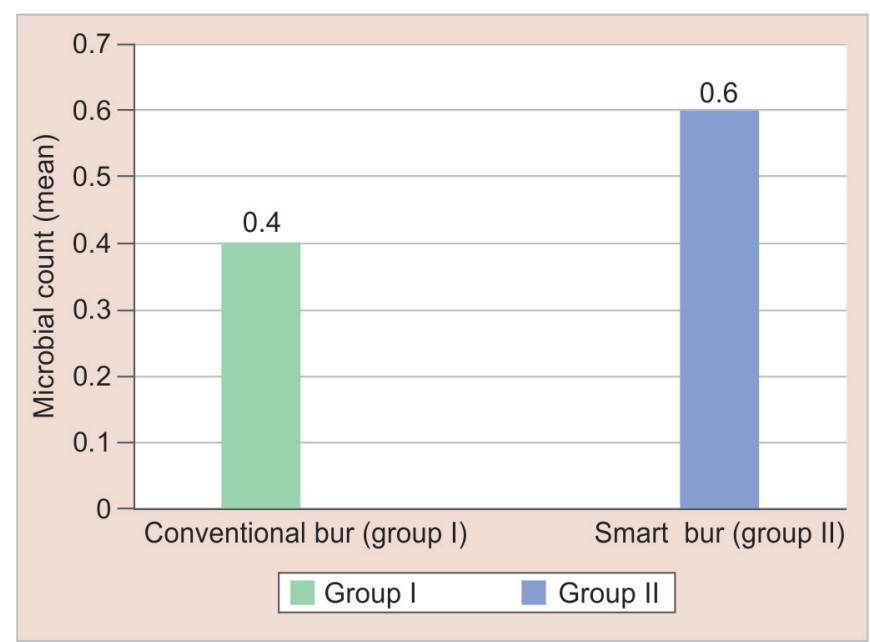

Fig. 3: Bar diagram showing the mean microbiological values for both the groups

( $p>0.05)$. Thus, it was observed that polymer burs are as effective as conventional burs in caries removal (Table 1 and Fig. 3).

Time duration for caries removal was observed for both the groups. On inter-group comparison between conventional bur (group I) and smart bur (group II), the difference was found to be statistically significant with a $p$ value of $0.001(p<0.05)$, showing higher time consumption by smart burs (Table 2 and Fig. 4).

\section{Discussion}

Conserving healthy tooth structure is a critical component of today's restorative dentistry. With the advancement, the G.V. Black's concept of "Extension for Prevention" has been changed to "Conservation for Prevention".7 To avail this concept, the Minimal intervention techniques has been introduced that involve the use of newer modalities such as Lasers, Enzymes like pronase, Chemomechanical removal of caries via Caridex and Cariosolv, and caries removal by Polyamide burs (Polymer Smartpep bur). ${ }^{8}$

It has been very well stated by Freedman and Goldstep ${ }^{9}$ polymer burs remove carious dentin selectively, whereas healthy dentin is not affected. The polymer cutting edges will wear down in contact with harder materials (such as healthy dentin) and will go blunt. Thus, the SmartPrep instruments are self-limiting and determined for single-use only.

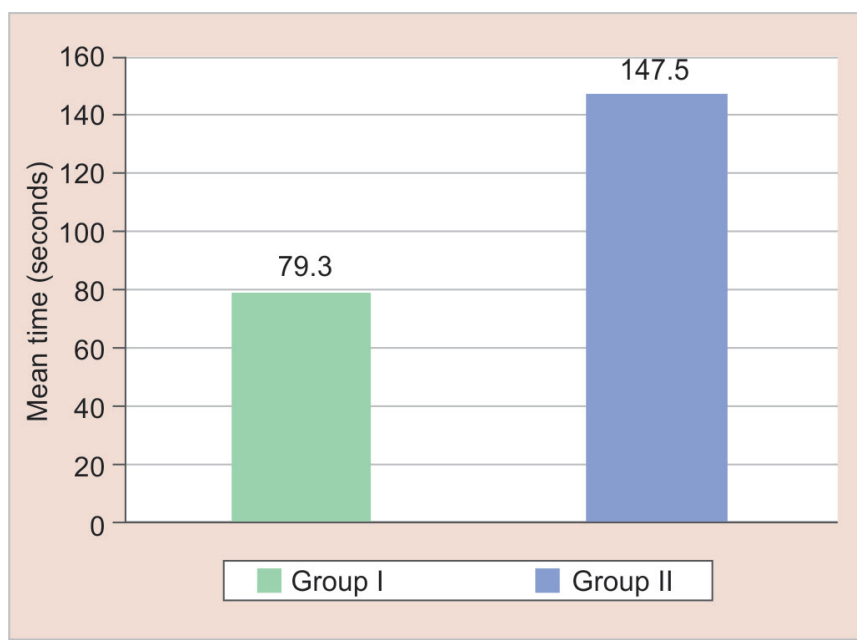

Fig. 4: Bar diagram showing mean time taken for caries removal in both the groups

A split-tooth methodology was used in the present study to standardize the amount of caries removal by both the burs. Banerjee et al. ${ }^{8}$ used split tooth method to evaluate five alternative methods of carious dentine excavation and Isik et al. ${ }^{10}$ also used the split tooth method to compare the caries removal efficiency of polymer burs and conventional carbide burs microbiologically.

In the present study, conventional burs removed more micro-organisms as they have greater knoop hardness of 7,000 $\mathrm{KHN}$ due to which it has greater cutting efficiency and remove both affected and infected dentin. However, smart burs have a knoop hardness of $50 \mathrm{KHN}$, which is higher than carious, softened dentin (0-30 KHN) but is softer than healthy dentin (70-90 KHN), making it efficient in removing only the infected dentin and involuntarily affected dentin is left behind. It has been reported that affected dentin is not completely devoid of microorganisms, but it contains minimal amount of microorganisms that remain behind in the dentinal tubules even after caries removal. This might be the reason of higher microbial count seen in samples where caries were removed by smart burs. Aswathi et al. ${ }^{11}$ found the same results of polymer burs being more efficient in reducing the total viable count. Similar results were also shown by Divya et al. ${ }^{12}$ in their comparative study on efficacy of caries removal using polymer bur, conventional bur, Carisolv and Papacarie with 
polymer bur containing the maximum microorganisms $(96.7 \%)$ after caries removal.

The time required for removal of caries with smart bur removal method took an average of 147.5 seconds when compared to conventional bur, which took only 79.3 resulting in a statistically significant difference between both the groups ( $p$ value $=0.001$ ). The possible reason would be the higher hardness number $(7,000$ $\mathrm{KHN}$ ) and higher cutting efficiency of the diamond bur. However, polymer bur has a hardness of just $50 \mathrm{KHN}$. Moreover, its cutting surface comprises of paddle-shaped flutes with blunt ends and are lesser in number, which results in longer time to remove the carious lesion. The studies conducted by Prabhakar et al. ${ }^{13}$ and Shakya et al. ${ }^{7}$ also supported more time consumption in caries removal by smart burs compared to conventional burs.

\section{Conclusion}

Within the limitations of the present study, it can be concluded that caries removal by polymer bur in cavitated teeth was comparable to that of the conventional burs in terms of mean microbial count in remaining dentin after caries removal. Although time taken by smart burs was more, it still could be a suitable, minimally invasive and hassel-free alternative method for caries removal. We recommend further studies to authenticate these results. Thus, it is recommended to use smart burs for caries removal for preservation of sound tooth structure.

\section{References}

1. Fusayama T. Two layers of carious dentin: Diagnosis and treatment. Oper Dent 1979;4:63-70.

2. Ogushi K, Fusayama T. Electron microscopic structure of two layers of carious dentin. J Dent Res 1975;54:1019-1026. DOI: $10.1177 / 00220345750540050301$.
3. Usha C, Ranjani R. Comparative evaluation of two commercially available polymer burs for their efficacy on dentinal caries removal Split tooth study using polarized light microscopy. J Sci Dent 2012;2(2):66-69.

4. Dammaschke T, Rodenberg TN, et al. Efficiency of the polymer bur smartprep compared with conventional tungsten carbide bud bur in dentin caries excavation. Oper Dent 2006;31(2):256-260. DOI: 10.2341/05-24.

5. US Department of Labor, Occupational Safety and Health Administration. Occupational exposure to blood-borne pathogens; final rule. Fed Reg 1991;56:64003-64182.

6. Bancroft JD, Stevens A. Theory and practice of histological techniques. 1990;3:112-117.

7. Shakya VK, Chandra A, et al. A comparative evaluation of dentin caries removal with polymer bur and conventional burs - An in vitro study. Open J Stomatol 2012;2:12-15. DOI: 10.4236/ojst.2012.21002.

8. Banerjee A, Watson TF, et al. Dentine caries excavation: A review of current clinical techniques. Br Dent J 2000;188:476-482. DOI: 10.1038/ sj.bdj.4800515.

9. Freedman G, Goldstep F. Polymer preparation instruments. New paradigm in selective dentin removal. Dent Today 2003;22(4):58-61.

10. Isik EE, Olmez A, et al. A microbiological assessment of polymer and conventional carbide burs in caries. Pediatr Dent 2010;32: 316-323.

11. Aswathi KK, Rani PS, et al. Comparison of efficacy of caries removal using polymer bur and chemomechanical caries removal agent: A clinical and microbiological assessment - An in vivo study. J Indian Soc Pedod Prev Dent 2017;35:6-13. DOI: 10.4103/0970-4388. 199232.

12. Divya G, Prasad MG, et al. Evaluation of the efficacy of caries removal using polymer bur, stainless steel bur, carisolv, papacarie - An in vitro comparative study. J Clin Diagn Res 2015;9(7):42-46. DOI: 10.7860/ JCDR/2015/12705.6202.

13. Prabhakar A, Kiran NK. Clinical evaluation of polyamide polymer burs for selective carious dentin removal. J Contemp Dent Pract 2009;10(4):26-34. 